\title{
Elements of Gamification in the Practice of Language Training for the Students of Technical and Managerial Areas
}

\author{
Astafeva A.E. \\ Foreign Languages in Professional Communication \\ Department \\ Kazan National Research Technological University \\ Kazan, Russia \\ adastafeva@gmail.com
}

\author{
Dulalaeva L.P. \\ Foreign Languages in Professional Communication \\ Department \\ Kazan National Research Technological University \\ Kazan, Russia \\ adastafeva@gmail.com
}

\author{
Semushina E.Y. \\ Foreign Languages in Professional Communication Department \\ Kazan National Research Technological University \\ Kazan, Russia \\ adastafeva@gmail.com
}

\begin{abstract}
The relevance of this study is due to the need for searching perspective ways to organize interactive learning for modern students of generation $\mathrm{Y}$ and $\mathrm{Z}$, who are highly involved in computer games. As an interactive teaching method it is proposed to introduce gamification elements into the educational process.

The aim of the study is to obtain experimental results of the gamification elements influence in the process of language training of students of technical and managerial areas on their academic progress.

The main research method is a pedagogical experiment (stating, formative and control stages). Theoretical research methods were also used, including analysis, comparison and synthesis of scientific results. Empirical methods were used summarizing and grouping of research results, information processing software. Interview and observation methods were used to collect primary information.

For the first time, the progress in students` studies and their attendance during language training with elements of gamification was experimentally recorded. This was due to increased motivation, engagement and cohesion of students with a more marked result for the technical students.

The authors' experience in developing the methodology of the game and the results of its implementation will be useful for further gamification of language training.
\end{abstract}

Keywords-gamification; motivation; involvement; academic progress; pedagogical experiment.

\section{INTRODUCTION}

Modern educational standards of preparation for undergraduate programs provide for the allocation of interactive training hours in addition to traditional types of lectures and seminars. In a series of this study authors works identified that the use of interactive teaching methods, in particular business games, in the course of conducting classes in a foreign language allows to improve the level of practiceoriented foreign terminology, to develop communication skills, foster creative thinking of students, and so on [1-3].
The problem of widespread introduction of interactive methods in the educational process is some resistance to their use by teachers. Indeed, an additional burden is placed on the teacher to develop the content, procedure and system of learning outcomes evaluation with the use of interactive cases, projects, business games, etc. The situation is complicated by low motivation of students to study general subjects in general and English in particular.

The relevance of this study is due to the need to find promising ways to organize interactive learning for modern students of generations $\mathrm{Y}$ and $\mathrm{Z}$ [4], characterized, among other things, by high involvement in interaction with the virtual environment and immersion in computer games [5]. The introduction of gamification elements into the educational process is proposed as a method of interactive learning.

\section{LITERATURE REVIEW}

The introduction of the term "gamification" is associated with the name of N. Pelling (2002) [6], and the wide spread of this phenomenon in the business sphere and its gradual introduction into other spheres of activity, with the names of G. Zickermann (2010) and K. Verbach (2012). So, Mr. Straman initiated the international agrification forum, Werbach K. introduced a course on gamification into educational process [7], which sparked interest from both scientific community and business representatives to use the method.

Based on the content analysis of the gamification definition produced by Dynkina E. D. according to the results of scientific publications of various authors, it can be noted that this method involves the use of gaming technologies in non-gaming spheres; the introduction of pleasure elements in activities that do not deliver it; the development of gaming thinking on the basis of computer-gaming techniques [8]. In 
The leading method of this problem research is pedagogical experiment (ascertaining, forming and control stages). Theoretical research methods were also applied, including analysis, comparison, synthesis, classification and generalization of scientific results. Empirical methods were used, such as literary and retrospective analysis, methods of summarizing and grouping research results, methods of software information processing. To collect primary information, we analyzed the statements and journals of teachers of the selected areas training for 5 years, used a survey and observation.

The place of the experiment was Kazan national Research Technological University (KNITU), Department of "Foreign languages in professional communication", natural learning conditions. Two parallel identical experiments were carried out in groups of students of the directions of training "Applied mathematics and Informatics" and "Management". In each direction of training, two groups (one control and one experimental) with similar performance indicators in the discipline "Foreign (English) language"were selected.

The period of the experiment covered the 4th semester of learning English (2nd semester of the 2nd year of study). During this period, according to the curriculum and work program, language training acquires a professional orientation. The calendar period of the experiment - spring semester, 2019. The average number of students in groups 22 people.

The final criterion for evaluating the results of the experiment was academic performance, but the components affecting it, such as motivation, involvement, cohesion and attendance, were also evaluated.

At the ascertaining stage of the experiment (FebruaryMarch), academic performance was assessed according to the results of traditional intermediate certification (testing, translation, retelling, answers to questions, discussion on texts). Participants - all groups. The formative stage involved the game "Prospects and limitations of the digital environment in education". Participants - on one group from each direction of preparation, the second groups in each direction-control. At the control stage, the final testing of both experimental and control groups was carried out. lack of understanding by students of the need for a foreign language in professional activities, which reduces their motivation to learn and involvement in work. On the other hand, generations $\mathrm{Y}$ and $\mathrm{Z}$ are open to interactive interactions and the digital environment, which allows us to recommend the introduction of gamification elements in the educational process.

Thus, for the introduction of gamification elements in the practice of students of technical and managerial specialties language training, it is necessary to develop a methodology for the game, the effectiveness of which can be evaluated during the pedagogical experiment.

\section{RESEARCH METHODOLOGY}

The aim of the study is to obtain experimental results of the gamification elements influence in the process of language training of students of technical and managerial areas on their academic performance.

\section{RESULTS}

\section{A. Ascertaining step.}

According to the analysis of statements, and magazines of academic achievement in groups of students training areas "Applied mathematics and Informatics" (for 2 groups) and "Management" (for 2 groups) 4 semester 2014-2017, and the results of interim certification during the first half of the spring semester 2019 the following average distribution of the ratings (on key statements) was established:

- "Applied mathematics and Informatics": excellent$28 \%$, good-52\%, satisfactory-17\%, failed - $3 \%$.

- "Management": excellent-37\%, good-51\%, satisfactory- $11 \%$, failed - $1 \%$. 
which will contribute to achieving the ultimate goal of the experiment.

The game was held in the second half of the 4th semester, after processing the results of the ascertaining experiment. Experimental groups, one from each direction of training, were divided into subgroups of 4-5 people, only 4 subgroups. The second groups in each direction of training were control. The subgroups received a task for independent work, the discussion and progress of which was supervised by the teacher within the hours of interactive training. Each subgroup received a sub-topic for the study:

- "Prospects and limitations of electronic document circulation".

- "Prospects and limitations of electronic libraries: EBC "Knigafond", EBC "LAN", EBC "University library", etc.

- $\quad$ "The prospects and limitations of electronic systems for verification of originality".

- "Prospects and limitations of scientific publications electronic databases: e-library, Web of Knowledge ScienceDirect, etc.

The choice of topics is predetermined not only by the trend of global digitalization of education, but also by the practical value of digital resources specified in the sub-themes for further education and research activities of students. The subgroup will have sub-themes randomly, by drawing cards with their names. Roles in groups were distributed as follows: "journalist" - 1 person, "spy" - 1 person, "assistant journalist" 1 person, "assistant spy" - 1 person (if subgroups of 4 people), "mediator" 1 person (if subgroups of 5 people). Collection of information by members of the subgroup is carried out within a month.

Thus, the "Journalist" collects data from open sources about the general concept of the digital system specified in the sub-topic, the result is a report for 5 minutes with a presentation. Work "journalist" and "assistant journalist" build together, because the task of "assistant journalist" to make a report on the prospects (advantages), ease of use, etc. advantages of systems.

"Spy" gets a job to find in KAZAN a Department responsible for work with these systems, figure out the order of works in digital systems, depending on sub-topics. Work " spy " and "assistant spy" build together, because the task of "assistant spy" to make a report on the shortcomings, problems, limitations of systems. "Mediator" (if available) summarizes all the "pros" and "cons" stated by previous speakers, "reconciling the parties".

To avoid duplication of information the speakers have to cooperate and plan together as a team. Reports (for 5 minutes), presentations and work in the audience is conducted in English. In addition, the active participation of the subgroup and other subgroups members in supporting opposing opinions (in the discussion) and fixing errors of lexical and grammatical constructions of speakers (when detected) and their discussion purpose of in increase motivation to learn the language, increase involvement in the learning process, form group cohesion, 
$55 \% / 51 \%$, satisfactory-11/19\% (decrease by $8 \%$ ), failed $-0 / 1 \%$.

to report in the last month of the semester.

Important for the dynamic conduct of the game is a system of levels, ratings and other scales of evaluation, allowing to assess the progress of both the individual and the group. The developed evaluation system for this experiment is multilevel and will be described in separate publications.

The general principle of a specially developed digital tool for evaluating results involves obtaining certain types of "smiles" for the level of linguistics, completeness, logic, clarity of the material presentation, support for another participant in case of difficulty with the answer, participation in dialogue, etc.

A certain number and type of "smile" will lead to the level of "specialist" / "master" / "expert", which gives additional "life" (in this case - the right to make a mistake), which can be shared with another participant. Progressive assessment scale, level system close to computer games, visualization of the progress of an individual and a subgroup is perceived by students much more positively, relative to point-rating methods.

\section{Control stage}

Mandatory for the control stage is the organization of the final generalizing classes on traditional methods (grammar, vocabulary, reading, retelling, questions, discussion) in both experimental and control subgroups, before the final exam.

Parameters reflecting their indicators, results of control registration of behavior and progress can be presented as follows (experimental / control groups):

- motivation for the criterion desire to give the answer first (a quick job and the show of hands): "Applied mathematics and Informatics" - 8 people/3 person (growth in 2,6 times) and "Management" - 7 people/4 people (an increase of 1.75 times).

- involvement, according to the criterion of desire to participate in the discussion, ask questions: "Applied mathematics and Informatics" - 14 people/6 people $(2.3$ times increase) and "Management" - 16 people/10 people (1.6 times increase).

- cohesion, according to the criterion of the desire to give explanations and help with the answer in case of difficulties for another member of the group: "Applied mathematics and computer science" - 6 people/2 people (an increase of 3 times) and "Management" - 10 people/6 people (an increase of 1.7 times).

Attendance was assessed for the entire period of the experiment and averaged $96 \%$ for experimental groups and $80 \%$ for control groups. Distribution of marks by results of final examination on the average on two experimental and two control groups (testing, traditional work with the text, answers to questions of the teacher):

- "Applied mathematics and Informatics" (experiment / control): excellent-34\% / 29\% (increase by 5\%), good-
- "Management": excellent-49\% / 36\%, good-55/52\%, satisfactory- $6 / 10 \%$, failed- $1 / 2 \%$.

The distribution of estimates in the control groups is close to that obtained at the ascertaining stage of the experiment. There is a significant increase in motivation, involvement, cohesion and, as a consequence, attendance and progress in experimental groups, with more significant results for the direction of " Applied mathematics and Informatics».

\section{DISCUSSION}

The positive influence of gamification on cognitive activity (R. M. Serikova, 2017), the development of dialogue 2017), experience and achievements of students (M. Lerning, 2015), etc. However, these studies are descriptive of the order of games and their potential effectiveness.

Works on the introduction of gamification in the process of Guro-Frolova (2016), O. V. Orlova (2016) have a debatable nature with elements of setting gamification options. However, there are no comprehensive experimental studies of the gamification effectiveness, with the presentation of the results of the experiment. Also, there are no publications that establish differences in the response to the introduction of gamification between students of technical and managerial areas.

In this research, for the first time an increase in academic performance and attendance of students in the course of language training with elements of gamification, due to increased motivation, involvement and cohesion of students, with a more pronounced result for technical areas of training was experimentally recorded.

This effect can be explained as initially a higher communication skills of students of a direction "Management", and elements of digital technology in the game, close the direction of "Applied mathematics and Informatics", which increased interest in individual and group work last.

\section{CONCLUSIONS}

Theoretical substantiation of gamification elements introduction potential in practice of language training of students both technical, and administrative directions of preparation is resulted. The methodology of the experiment with the description of the order of organization of the role-

For the first time, the growth of students ' progress and attendance in the course of language training with elements of gamification was experimentally registered, due to the increase in motivation, involvement and cohesion of students, with a more pronounced result for technical areas of training.

Motivation, according to the criterion of the desire to give the answer first, in the experimental group of the direction thinking (R. S. Tsareva, 2017), motivation (T. M. Labusheva, language training, for example, A. A. Fadeeva (2018), Yu.R. playing game and its evaluation is presented. 
[5] B.P. Diakonov. Gamification in asynchronous educational process. Historical and socio-educational thought. 2016, vol. 8, 1-1, pp. 143-147.

"Applied mathematics and computer science" increased by 2.6 times; "Management" - by 1.75 times. Involvement, according to the criterion of the desire to participate in the discussion, ask questions increased: "Applied mathematics and computer science" - 2.3 times; "Management" - 1.6 times. Cohesion, according to the criterion of the desire to give explanations and help with the answer in case of difficulties for another member of the group, increased: "Applied mathematics and computer science" by 3 times; "Management" by 1.7 times.

The number of excellent grades in the direction of "Applied mathematics and Informatics" increased by 5\%, satisfactory grades decreased by $8 \%$, which allows us to recommend the introduction of gamification elements in the educational process of various areas of training of students.

\section{References}

[1] A.E. Astafyeva. Interactive learning in language training of students of the direction 'management'. Scientific review: humanitarian studies. 2017, 3, pp. 36-39.

[2] A.E. Astafyeva. Development of professional English-language communication through business games. Scientific review: humanitarian studies. 2017, 4, pp. 55-59.

[3] L.P. Dulalaeva. Business game in teaching professional foreign language communication. Modern problems of science and education. 2015, 6, pp. 476.

[4] E.A. Yankova, A.V. Melnichuk. Gamification as a tool to increase the involvement of personnel of the organization. Materials of Ivanovo readings. 2017, 3-1 (14), pp. 194-200.
[6] A.V. Ssyrkina, E.A. Vetrova. Gamification in teaching students of conflict studies. New generation. 2016, 9, pp. 156-163.

[7] O.Y. Zorina, E.V. Povorina. Gamification as a phenomenon of the modern world. New generation. 2016, 9, pp. 73-79.

[8] E.D. Dynkina. Gamification as a tool to improve the efficiency of personnel training. Business education in the knowledge economy. 2017, 2(7), pp. 51-57.

[9] V.V. Bulgakov, A.A. Lazarev, E.P. Konovalenko, T.A. Mochalova. Game method of practical training of officers of the state fire service. Education and science. 2019, vol. 21, 4, pp. 183-207.

[10] I.V. Iilyina, N.A. Tarsuk, O.M. Novikova. Communicative competence formation of teachers in the sphere of foreign language education in the system of the advanced training. European journal of contemporary education. 2018, 7(4), pp. 699-709.

[11] M.E. Baskakova, I.V. Soboleva. New facets of functional illiteracy in the digital economy. Education Issues. 2019, 1, pp. 244-263.

[12] M.N. Kalyar, B. Ahmad, H. Kalyan. Does teacher motivation Affect student motivation. The mediating role of professional behavior of the teacher. Eeducation Issues, 2018, 3, pp. 91-119.

[13] Yu.R. Guro-Frolova. Gamification of the process of teaching a foreign language in the framework of e-learning technologies. E-learning in continuing education. 2016, 1, pp. 684-690.

[14] Alexsandr S. Kuznetsov. Russian Professor's meeting. Russian Journal of Physical Education and Sport. 2019, 14(1), pp. 17-22. DOI: 10.14526/2070-4798-2019-14-1-18-24

[15] K. Robson, K. Plangger, J. Kietzmann, I.P. McCarthy, L. Pitt. Is It All a Game? Understanding the Principles of Gamification. Business Horizons. 2015, vol. 58, 4, URL: https://ssrn.com/abstract=2635587. 